\title{
Método rápido para detección de bacteriuria en examen microscópico de orina no centrifugada.
}

Daniel A. Luján-Roca, Giovanni R. Pajuelo-Camacho.

Universidad Nacional Federico Villarreal, Lima, Perú.

\section{RESUMEN.}

Objetivo. Evaluar la presencia de bacterias en la examinación microscópica de orina no centrifugada como indicador de bacteriuria significativa.

Material y métodos. Se procesaron 182 muestras de orina, tomando $30 \mu \mathrm{L}$ de cada una y procediendo con una tinción Gram para la examinación microscópica, cada muestra tuvo su urocultivo respectivo.

Resultados. Comparados con un cultivo $\geq 10^{5}$ ufc/ $\mathrm{mL}$ se obtuvieron valores de sensibilidad de $93.6 \% \mathrm{y}$ especificidad de $89.4 \%$.

Conclusiones. Se concluye que la técnica con asa de siembra tomando $30 \mu \mathrm{L}$ de orina no centrifugada puede ser usada para un diagnóstico presuntivo de infección de tracto urinario en la práctica bacteriológica. (Rev Biomed 2005; 16:169-173)

Palabras clave: Bacteriuria, urocultivo, tinción de Gram.

\section{Artículo Original}


DA Luján-Roca, GR Pajuelo-Camacho.

\section{INTRODUCCIÓN.}

Las infecciones del tracto urinario (ITU) se hallan entre las enfermedades infecciosas más frecuentes. Denota una amplia variedad de entidades patológicas, en las cuales el común denominador es la presencia de un número significativamente grande de microorganismos en cualquier porción del aparato urinario. Los microorganismos pueden hacerse evidentes sólo en la orina (bacteriuria) $(1,2)$ o puede haber señales de infección de algún órgano: uretritis, prostatitis, cistitis, pielonefritis. La mayor parte de las ITU ocasionan síntomas locales, aunque las manifestaciones clínicas no siempre indican el lugar de la infección (3-5).

El diagnóstico para ITU es el urocultivo cuantitativo, el cual hace posible diferenciar entre bacteriuria significativa (infección) y bacteriuria no significativa (bacterias introducidas en la uretra distal) $(6,7)$. El urocultivo presenta un gran volumen de muestras en el laboratorio consumiendo por lo tanto material, personal de laboratorio, tiempo y generalmente da un resultado negativo en un $80 \%$ de casos (8). En general, las infecciones activas del aparato urinario se caracterizan por dar cuentas bacterianas superiores a 100000 bacterias $/ \mathrm{mL}$. Aunque existen consideraciones en cuanto al cuadro clínico, bacteria y forma de obtención de la muestra (9).

Se han diseñado numerosos métodos para determinar bacteriuria significativa además del urocultivo: microscópicos, químicos, bioquímicos, enzimáticos, etc., pero un número mínimo logra ofrecer un costo adecuado y sencillez en la realización del análisis $(10,11)$.

Es posible establecer el diagnóstico presuncional de infección bacteriana basándose en los resultados del examen microscópico de orina no centrifugada con tinción Gram ya que correlaciona muy bien con $1 \times 10^{5} \mathrm{ufc} / \mathrm{mL}$. (12-14) y en el Perú se disponen de pocos estudios comparativos.

\section{MATERIAL YMÉTODOS. Muestras.}

El presente estudio de investigación se llevó a cabo en el Laboratorio de Microbiología del Hospital Santa Rosa en Lima, Perú, entre noviembre y diciembre de 2004. Se seleccionaron 182 muestras de orina de pacientes ambulatorios y hospitalizados a quienes se les solicitó el examen de urocultivo. Una higiene básica y precauciones asépticas fueron tomadas para obtener todas las muestras de orina. El tiempo entre la colección y el cultivo nunca excedió las dos horas.

\section{Criterios de inclusión.}

Fueron incluidos pacientes a quienes se les ha solicitado examen de urocultivo, sin tener en cuenta sintomatología, sexo, edad y cuya muestra de orina estuviese adecuadamente colectada y exenta de algún tipo de contaminación.

\section{Criterios de exclusión.}

Fueron excluidos pacientes cuyas muestras mostraran evidencias de una inadecuada colección, presencia de antibióticos, contaminación con flujo vaginal, heces o pérdida de datos de importancia para el análisis comparativo.

\section{Método con ASA calibrada.}

Posterior a la homogenización de la muestra de orina un volumen de $10 \mu \mathrm{L}$ fue tomado por medio de un asa calibrada de cromo-níquel y aplicada sobre un portaobjetos. Esta operación se repitió en tres ocasiones para tener un volumen de $30 \mu \mathrm{L}$, luego se diseminó la muestra en el portaobjetos y se llevó a la estufa a secar.

\section{Tinción Gram.}

Después del secado el frotis fue fijado pasando dos o tres veces a través de un mechero Bunsen y se procedió con la tinción por el método Gram.

\section{Examinación microscópica.}

La lectura microscópica fue realizada a un aumento de 100x con objetivo de aceite de inmersión. Fueron examinados 20 campos y el número de microorganismos por campo fue registrado y se obtuvo un promedio de ellos. Una examinación microscópica positiva fue definida como la presencia de $\geq 1$ bacterias uniformemente distribuidas por 
Detección de bacteriuria en orina no centrifugada.

campo de aceite de inmersión.

\section{Cultivo.}

Una cantidad de $10 \mu \mathrm{L}$ de orina fue inoculada sobre agar Mc Conkey y CLED utilizando asa calibrada y estriada para la determinación del conteo de colonias. Los cultivos fueron incubados a $35^{\circ} \mathrm{Cy}$ la lectura se realizó a las 24 y 48 horas. Las ufc/mL fueron estimadas multiplicando el número de colonias por 100 .

Análisis de los datos.

La comparación de la eficiencia diagnóstica de la técnica con el urocultivo se efectuó calculando la sensibilidad, especificidad y valores predictivos.

\section{RESULTADOS.}

Se analizaron 182 muestras de orina, la edad promedio de los pacientes fue de 43.2 años. De las 182 muestras analizadas, 134 provinieron de mujeres y 48 de hombres. El total de los urocultivos positivos fue de 31 (17\%). Un total de 26 mujeres (19.4\%) y 5 hombres $(10.4 \%)$ tuvieron cultivos positivos.

Correspondiente al recuento de bacterias se obtuvo el siguiente resultado: sensibilidad 93.6\%, especificidad $89.4 \%$, valor predictivo positivo $64.0 \%$, valor predictivo negativo $98.5 \%$ (cuadro 1).

\section{Cuadro 1}

Correlación" entre examinación microscópica de bacterias y el resultado de cultivos de $\mathbf{1 8 2}$ muestras de orina.

\begin{tabular}{lccr}
\hline $\begin{array}{l}\text { resultado } \\
\text { de examen } \\
\text { directo }\end{array}$ & positivo $^{\dagger}$ & negativo & total \\
\hline positivo & $29(\mathrm{a})$ & $16(\mathrm{~b})$ & 45 \\
negativo & $2(\mathrm{c})$ & $135(\mathrm{~d})$ & 137 \\
total & 31 & 151 & 182 \\
\hline
\end{tabular}

${ }^{*}$ Sensibilidad $[\mathrm{a} /(\mathrm{a}+\mathrm{c})]=29 / 31(93.6 \%)$; Especificidad $[\mathrm{d} /(\mathrm{d}+\mathrm{b})]=135 / 151$ (89.4\%); Valor Predictivo Positivo $[\mathrm{a} /(\mathrm{a}+\mathrm{b})]=29 / 45(64.0 \%)$; Valor Predictivo Negativo $[\mathrm{d} /(\mathrm{d}+\mathrm{c})]=135 / 137(98.5 \%)$

$\dagger$ Conteo de colonias $\geq 10^{5} \mathrm{UFC} / \mathrm{ml}$.

$\ddagger$ Observación $\geq 1$ bacteria por campo en aceite de inmersión

\section{DISCUSIÓN.}

Los métodos evaluados en este estudio proveen resultados en minutos, no requieren instrumentación y son fáciles de realizar. En la presente investigación se eligió utilizar examinación microscópica de orina no centrifugada con tinción de Gram, porque ésta es considerada la más fácil de realizar y la menos costosa, probablemente el más sensible y confiable método diagnóstico para analizar muestras de orina conteniendo más de $10^{5} \mathrm{ufc} / \mathrm{mL}$.

Aunque el examen microscópico de una gota de orina no centrifugada, con tinción Gram, es reconocido como un método microscópico convencional para el diagnóstico de muestras de orina con recuentos $\geq 10^{5}$ $\mathrm{ufc} / \mathrm{mL}$, siendo recomendado como procedimiento de rutina en la práctica bacteriológica por algunos autores, ninguna técnica estandarizada existe para realizar este procedimiento en el laboratorio microbiológico (15).

Para la elección de los métodos aquí utilizados se revisaron metaanálisis, en los cuales se revisó sistemáticamente y se resumió la literatura existente respecto al rendimiento de pruebas de diagnóstico rápidas para infecciones de tracto urinario (16-18).

Para el hallazgo de bacterias la sensibilidad ha sido de $93.6 \%$, lo que representa la probabilidad de clasificar correctamente a un individuo enfermo, es decir, la probabilidad de que para un sujeto enfermo se obtenga en la prueba un resultado positivo. Esta sensibilidad es, por lo tanto, la capacidad de la prueba para detectar la enfermedad.

La especificidad reportada se ha determinado en $89.4 \%$, lo que representa la probabilidad de clasificar correctamente a un individuo sano, es decir, la probabilidad de que para un sujeto sano se obtenga un resultado negativo, pudiéndolo precisar como la especificidad es la capacidad de detectar a los sanos. La detección de bacteriuria significativa por examinación microscópica de orina no centrifugada, ha sido descrita en varios estudios (19-26), en los cuales los autores han encontrado sensibilidades de $85.2,80,98.9,81,94.1,96.2,92.9$ y $96 \%$, respectivamente.

En cuanto a los valores predictivos, se obtuvo un valor predictivo positivo de $64.0 \%$, lo que 


\section{DA Luján-Roca, GR Pajuelo-Camacho.}

representa la probabilidad de padecer la enfermedad si se obtiene un resultado positivo en el test. En cuanto al valor predictivo negativo para la prueba se obtuvo $98.5 \%$, lo que representa la probabilidad de que un sujeto con un resultado negativo en la prueba esté realmente sano.

La principal ventaja de realizar examinación microscópica de orina no centrifugada con tinción Gram, como parte de la rutina bacteriológica de cultivos de orina, es el diagnóstico presuntivo rápido de infección urinaria y como guía para el tratamiento inicial basado en la forma y propiedades a la tinción del probable agente etiológico infectivo; en resumen, los resultados en la presente investigación demuestran que el método con asa de siembra $(30 \mu \mathrm{L})$ puede ser utilizado para detectar bacteriuria significativa con la ventaja de una gran rapidez y simplicidad para su ejecución.

\section{AGRADECIMIENTOS.}

Nuestro sincero agradecimento al Bioestadístico Ronald Torres por el análisis de los datos.

\section{REFERENCIAS.}

1.- Kass EH. Bacteriuria and diagnosis of infections of the urinary tract. Arch Intern Med 1957; 100: 709-14.

2.- Platt R. Quantitative definition of bacteriuria. Amer J Med $1983 ; 75: 44-52$.

3.- Fairley K, Carson N, Gutch R, Leighton P, Grounds A, Laird E, et al. Site of infection in acute urinary tract infection in general practice. Lancet 1971;2:615-8.

4.- Ronald A, Boutros P, Mourtada H. Bacteriuria localization and response to single-dose therapy in woman. JAMA 1976; 235: 1854-6.

5.- Boutros P, Mourtada H, Ronald A. Urinary infection localization. Am J Obstet Gynecol 1972; 112: 379-81.

6.- Jodal U, Lindberg U. Guideline for management of children with urinary tract infection and vesico-ureteric reflux. Recommendations from a Swedish state-of-the-art conference. Acta Paediatr 1999; 431 (Suppl): 87-9.
7.- Norman DC, Yamamura R, Yoshikawa T. Pyuria: its predictive value of asymptomatic bacteriuria in ambulatory elderly men. J Urol 1986; 135: 520-2.

8.- Kolbeck J, Padgett R, Estevez E, Harrell L. Bioluminiscence screening for bacteriuria. J Clin Microbiol 1985; 21: 527-30.

9.- Saito A, Kawada Y. Reliability of pyuria detection method. Infection 1994; 22(suppl 1): 36-7.

10.- Hoberman A, Wald E. Pyuria and bacteriuria in urine specimens obtained by catheter from young children with fever. J Pediatr 1994; 124: 513-9.

11.- Pezzlo M, Ige V, Woolard A, Peterson E, Maza de la L. Rapid bioluminescence method for screening. J Clin Microbiol 1989; 27: 716-20.

12.- Berger SA, Bogokowsky B, Block C. Rapid screening of urine for bacteria and cells by using a catalase reagent. $J$ Clin Microbiol 1990; 28: 1066-7.

13.- Pezzlo M, Ámsterdam D, Anhalt J, Lawrence T, Stratton $\mathrm{N}$, Vetter E, et al. Detection of bacteriuria and pyuria by URISCREEN, a rapid enzymatic screening test. J Clin Microbiol 1992; 30: 680-4.

14.- Hoberman A, Wald E, Penchasky L, Reynolds E, Young S. Enhanced urinalysis as a screening test for urinary tract infection. Pediatrics 1993; 91: 1196-9.

15.- Virella G. Microbiology and infectious diseases. $3^{\text {th }}$ edition. Maryland: Williams and Wilkins; 1997.

16.- Gorelick M, Shaw K. Screenings tests for urinary tract infection in children: a meta-analysis. Pediatrics 1999; 104: 104-10.

17.- Huicho L, Campos-Sanchez M, Alamo C. Metaanalysis of urine screening tests for de-termining the risk of urinary tract infection in children. Pediatr Infect Dis 2002; 21: 1-11.

18.- Deville W, Yzermans J, Duijn van J, Bezemer P, Wind van der D, Bouter $\mathrm{L}$. The urine dipsticks test useful to rule out infections. A meta-analysis of the accuracy. Br Med Clin Urology 2004; 4: 4-17.

19.- Dayan P, Bennett J, Best R, Bregstein J, Levine D, Novick M, et al. Test characteristics of the urine gram stain in infants 60 days of age with fever. Pediatr Emerg Care 2002; 18: 12-4.

\section{Revista Biomédica}




\section{Detección de bacteriuria en orina no centrifugada.}

20.- Arslan S, Caksen H, Rastgeldi L, Uner A, Oner A, Odabas D. Use of urinary gram stain for detection of urinary tract infection in childhood. Yale J Biol Med 2002;

75:73-8.

21.- Benito J, Garcia R, Trebolazabala N, Mintegi S, Vasquez M, Urra E. Gram stain and dipstick as diagnostic methods for urinary tract infection in febrile infants. An Esp Pediatr 2000; 53:561-6.

22.- Shaw K, Mc Gowan K, Gorelick M, Sanford J. Screening for urinary tract infection in infants in the emergency department: which test is the best? Pediatrics 1998; 101: 15.

23.- Appelbaum P, Olmstead C. Evaluation of gram - stain screen and Micro - ID methods for direct identification of Enterobacteriaceae from urines. Med Microbiol Inmunol 1982; 170: 173-84.

24.- Tilton RE, Tilton RC. Automated direct antimicrobial susceptibility testing of microscopically screened urine cultures. J Clin Microbiol 1980; 11: 157-61.

25.- Wu T, Williams E, Koo S, McLowry J. Evaluation of three bacteriuria screening methods in a clinical research hospital. J Clin Microbiol 1985; 21: 796-9.

26.- Cardoso C, Barbosa C, Dias V, Guilhermetti M. Simplified technique for detection of significant bacteriuria by microscopic examination of urine. J Clin Microbiol 1998; 36: 820-3. 